January 2019

\title{
Chinese Graduate Student Understandings and Struggles with Critical Thinking: A Narrative-Case Study
}

Kyle J. Lucas

Purdue University, lucas91@purdue.edu

Follow this and additional works at: https://digitalcommons.georgiasouthern.edu/ij-sotl

\section{Recommended Citation}

Lucas, Kyle J. (2019) "Chinese Graduate Student Understandings and Struggles with Critical Thinking: A Narrative-Case Study," International Journal for the Scholarship of Teaching and Learning: Vol. 13: No. 1, Article 5.

Available at: https://doi.org/10.20429/ijsotl.2019.130105 


\title{
Chinese Graduate Student Understandings and Struggles with Critical Thinking: A Narrative-Case Study
}

\author{
Abstract \\ Qualitative research offers the potential to inform an ongoing issue concerning why international students \\ struggle with critical thinking. This article approaches the issue by examining how international graduate \\ students understand critical thinking as well as the challenges they have faced with critical thinking. The \\ study used a narrative-case study framework to collect data from 4 Chinese international graduate \\ students at a large mid-Western research university in the United States. The results showed that the \\ participants had diverse conceptions of critical thinking and that they tended to focus on dispositions \\ related to critical thinking rather than skills. These results suggest that participants' struggles may be \\ related to diverse conceptualizations of critical thinking as well as an overemphasis on dispositions. \\ Furthermore, educational differences between the U.S. and China were highlighted in the interviews with \\ the participants, which supports other findings in the literature.
}

\section{Keywords}

Critical Thinking, Qualitative Research, Critical Thinking Skills, Critical Thinking Dispositions

\section{Creative Commons License}

cc) $($ ) $९$

This work is licensed under a Creative Commons Attribution-Noncommercial-No Derivative Works 4.0 License. 


\title{
Chinese Graduate Student Understandings and Struggles with Critical Thinking: A Narrative-Case Study
}

\author{
Kyle J. Lucas \\ Purdue University
}

Received: 12 June 2018;Accepted I 3 August 2018

\begin{abstract}
Qualitative research offers the potential to inform an ongoing issue concerning why international students struggle with critical thinking. This article approaches the issue by examining how international graduate students understand critical thinking as well as the challenges they have faced with critical thinking. The study used a narrative-case study framework to collect data from 4 Chinese international graduate students at a large mid-Western research university in the United States. The results showed that the participants had diverse conceptions of critical thinking and that they tended to focus on dispositions related to critical thinking rather than skills. These results suggest that participants' struggles may be related to diverse conceptualizations of critical thinking as well as an overemphasis on dispositions. Furthermore, educational differences between the U.S. and China were highlighted in the interviews with the participants, which supports other findings in the literature.
\end{abstract}

Critical thinking (CT) has become an important topic the past decades in the scholarship of teaching and learning (SoTL), especially in higher educational contexts, where CT is often advocated as an important skill for academic success. Although researchers have not agreed on how CT should be conceptualized, advocates have often conceived of it as a cognitive skill that can be taught (Davidson, 1997; Sobkowiak, 2016). For example, in defining CT, Sobkowiak (2016) primarily draws upon Facione (1990), who characterizes CT as involving six core cognitive skills (analysis, interpretation, inference, evaluation, explanation, and self-regulation) as well as several dispositions (such as being fair-minded and open to alternative positions). In addition, recent research has started to explore how different pedagogical practices can foster the development of CT across various disciplines in higher education (e.g., Chaplin 2007; Kaddoura, 20 I I; Holmes, Wieman, \& Bonn, 20I5).

Similarly, in research on second language pedagogy, especially in English for Academic Purposes (EAP) contexts, CT has been viewed as an important skill to teach students, and some have argued that it should be incorporated throughout the EAP curriculum (Thompson, 2002; Stroupe 2006). However, despite this promotion and advocation of CT, a recent area of debate is why international, and especially Asian students, seem to struggle with CT (Floyd, 20I I; Tian \& Low, 20I I; Luk \& Lin, 20I5; and Vandermensbrugghe, 2004). Qualitative research methodologies offer the promise to make headway in this issue, as they allow for the obtainment of rich data about learner experiences. While past research has been conducted on $C T$ through qualitative lenses (e.g., Moore, 20I3; Nicholas, 20I I; Lloyd, \& Bahr, 20 I0; Phillips \& Bond, 2004; Facione, 1990), this research has primarily focused on definitional disputes surrounding CT. Qualitative research has not, however, been used to approach the issue from the perspective of international graduate students, which could offer useful insights into this debate. Accordingly, the purpose of this paper is to address this gap by using a narrative-case study framework to extract detailed accounts of graduate international students' experiences with $\mathrm{CT}$.

\section{DEFINING CRITICAL THINKING}

There has been a wide array of definitions offered for critical thinking in the literature. Moore (2013), for example, interviewed academics from history, philosophy, and cultural studies, asking them to define CT. He found seven definitional strands emerged from the interviews, including (I) judgement, (2) skepticism, (3) simple originality, (4) sensitive readings, (5) rationality, (6) activist engagement with knowledge, and (7) reflexivity. Likewise, Ryan and Louie (2007) have noted that there is a lack of common understanding about the term in academic circles.

While definitions have varied, several authors have attempted to define critical thinking as a set of cognitive skills and dispositions. For instance, Facione (1990) conducted a study in which critical thinking experts were tasked with reaching a consensus definition. The experts agreed on several skills (e.g., interpretation, analysis, inference, evaluation) and dispositions (e.g., being open-minded, inquisitive, fair-minded) that are possessed by critical thinkers. In a similar vein, Ennis (1998) lists abilities and dispositions of critical thinkers, several of which overlap with the definition offered above (e.g., abilities include analyzing arguments and making deductions, and dispositions include seriously considering alternative points of view and representing positions fairly and honestly). Finally, Paul and Elder (200I) define CT as involving universal intellectual standards and elements of thought (which can be related to skills and abilities) as well as intellectual traits and virtues (which are analogous to the dispositions noted above).

The skills and dispositions of the above definitions do not completely overlap; however, a common theme begins to emerge: Critical thinking involves the introspection of reasoning to improve thinking. As Weissberg (2013) succinctly puts it, what most definitions have in common is that they involve the use of reason to create depth in thinking. Thus, even though authors such as Moore (2013) found a wide array of definitions, one could argue that there is a common core. Nevertheless, while some definitions see CT as a generic skill (i.e., skills that can be applied across contexts and academic disciplines) others see it as an embedded skill, in which there is or needs to be specific content (Phillips \& Bond, 2004). Willingham (2008), for example, argues that thinking processes are intricately tied up with the content of thought, and Weissberg (2013) expresses a similar 
concern, which leads him to question whether CT can be taught. A related issue is the extent to which different disciplines draw upon different elements of CT. Nicholas and Raider-Roth (20I6), for example, found that faculty from different disciplines tended to teach CT elements that applied to their specific discipline, but not necessarily elements that could be applied across disciplines. The authors also noted that this practice tended to be at odds with the institutional approaches to teaching $\mathrm{CT}$, which tend to emphasize $C T$ as a generic ability rather than discipline-specific ability.

Another issue that has emerged in defining CT is whether the associated skills and dispositions are in part or entirely a socially constructed practice. Atkinson (1997), for example, argued CT is a social practice on grounds of the lack of definitional consensus as well as analogous features of CT with other social practices. Likewise, Benesch (1993) sees CT as involving the critique of power relations and social inequities, making it a democratic learning process. This perspective could help to explain the definitional difficulty of CT, for as Atkinson (1997) argues, social practices are by their nature implicit and, therefore, hard to explicate. Nevertheless, this position would also make CT practices controversial, since teaching CT might be biased against alternative ways of thinking. This perspective has also received support from research that has argued that cognitive processes are fundamentally shaped by one's social environment (e.g., Nisbett et al., 200 I), although this argument is disputed in the literature (e.g., see Murphy, 20I5; Chan \& Yan, 2007).

\section{Critical Thinking \& International Students}

Several authors have noted that critical thinking is especially challenging for international students. Multiple explanations have been discussed in the literature as to why this might be. First, some have argued that the background educational experiences of international students may have not adequately prepared them for CT.Tian and Low (20I I), for example, note that factors such as a lack of familiarity with the norms of discourse and domain specific knowledge could, in part, underlie this observation. Paton (2005) notes similar factors and also argues that this struggle is by no means unique to international students, but is a struggle faced by nearly all freshmen undergraduates. In addition, it could be that the skills and dispositions associated with CT have become more prominent in Western secondary educational contexts. For example, if international students have not previously been trained in, say, argument analysis - a skill advocated by Facione (1990) and Ennis (1998)—while some or a majority of their Western counterparts have, then we would expect such difficulties to arise.

Another explanation is that fundamental cultural differences account for the observed struggles. If, for example, CT is a social practice, then this struggle does not appear to be one of mastering a universally useful skill but of mastering a cultural behavior.Atkinson (1997), for example, sees CT as a Western social practice that involves individual dissensus and debate rather than cooperation and consensus, which he argues is promoted in other cultural contexts. Thus, in this case, CT would be challenging because the sociocultural context of certain international students has instilled them with different social behaviors than what is demanded from the critical thinker.

Finally, several authors have noted that international students face an additional language challenge that LI students do not (e.g., Vandermensbrugghe, 2004; Tian and Low, 20I I). As Floyd (20II) puts it "All students face challenges in this field, but international students face a double challenge: not only must they think critically, but the must think critically in a second language (L2)" (p. 289). Floyd's (20I I) study would go on to provide evidence that CT tests show different results when the test was conducted in a student's LI and L2. Luk and Lin (20I5) found similar results when observing the criticality and elaborateness of discourses produced by students in their LIs (Cantonese) and L2s (English). Thus, it may be that the observed difficulties associated with CT are not due to a lack of CT skills, but a lack of means whereby the students can express those skills.

Although research has started to look more extensively into the causes behind this issue, little research has attempted to use qualitative lenses to examine student perceptions. Phillips and Bonds (2004) is a notable exception; however, these authors examined undergraduate rather than graduate students, and they examined domestic rather than international students. Lloyd and Bahr (2010) also examined student perceptions of CT, comparing their perceptions with those of experts, but again, this study examined undergraduate perceptions. Because international graduate students have had more time to develop their cognitive abilities than international undergraduate students and because they likely will have had more exposure to CT, they offer a rich source of information that can inform this debate.According, the present study was designed to examine the perceptions and experiences that one group of international graduate students have had with critical thinking. In particular, two research questions guided this study:

I. How does one group of international graduate students understand and conceptualize critical thinking?

What aspects of critical thinking have they struggled with and found challenging?

\section{METHODS}

This research project utilizes a combination of a narrative and case study framework. A narrative framework was chosen as this allows researchers to examine how people experience the world and, more specifically, educational experiences (Connelly \& Clandinin, 1990). For this study, in order to understand what challenges international graduate students have had with $\mathrm{CT}$, it was deemed important that their educational experiences be elicited. In addition, the study also fits within a case study framework, as it examines a bounded system (Creswell, 20I3), i.e., the experiences of several participants within a particular context.

\section{Participants and Setting}

The study took place at a large Midwestern research university. The university has over 10,000 graduate students, and international students account for over $20 \%$ of the entire student population. Four participants took place in the study, all of whom were international graduate students from China. The study used a mix of convenience and criterion sampling (Creswell, 20l3) to select the participants. In regards to the sampling criteria, only participants who met the following conditions were selected:

- International

- Chinese

- Graduate level

- Completed high school in China 
The last condition was selected in order to assure that the participants did not complete their primary and secondary education in a Western context, as it is not uncommon for international students to attend high schools in the United States before beginning their postsecondary education. Table I below summarizes additional information about the participants, including their sex, LI, the time they have spent in the United States, the type of high school they attended and the medium of instruction, as well as their current graduate program.

\begin{tabular}{|l|l|l|l|l|l|}
\hline \multicolumn{6}{|c|}{ Table I. Participants } \\
\hline & Sex & $\begin{array}{l}\text { First } \\
\text { Language }\end{array}$ & $\begin{array}{l}\text { Time in } \\
\text { United } \\
\text { States }\end{array}$ & $\begin{array}{l}\text { High School } \\
\text { \& Medium of } \\
\text { Instruction }\end{array}$ & $\begin{array}{l}\text { Graduate } \\
\text { program } \\
\text { at Purdue }\end{array}$ \\
\hline $\mathbf{I}$ & Female & Mandarin & $\sim 1 / 2$ year & $\begin{array}{l}\text { Traditional; } \\
\text { Mandarin }\end{array}$ & $\begin{array}{l}\text { Mechanical } \\
\text { Engineering }\end{array}$ \\
\hline $\mathbf{2}$ & Female & Mandarin & $\sim 1 / 2$ year & $\begin{array}{l}\text { Traditional; } \\
\text { Mandarin }\end{array}$ & $\begin{array}{l}\text { Electrical and } \\
\text { Computer } \\
\text { Engineering }\end{array}$ \\
\hline $\mathbf{3}$ & Female & Mandarin & $\mathbf{I} 1 / 2$ years & $\begin{array}{l}\text { Traditional; } \\
\text { Mandarin }\end{array}$ & English \\
\hline $\mathbf{4}$ & Male & Mandarin & +3 years & $\begin{array}{l}\text { Traditional; } \\
\text { Mandarin }\end{array}$ & English \\
\hline
\end{tabular}

\section{DATA COLLECTION, CODING,} AND ANALYSIS

A semi-structured interview format was used for this study, and each interview lasted between 15-30 minutes. Compared to an unstructured interview, this format had the advantage of eliciting data more relevant to the research questions (Rabionet, 20 I I). One-on-one interviewing was used, and although focus groups might have proven advantageous since interviewees would likely have been more willing to share information (Creswell, 20l3), this was deemed problematic, as participants would have been more likely to avoid discussing unique problems. Interviews were selected as the method for gathering data because this research project aims to better understand participants' difficulties and challenges from an emic perspective; since such experiences lie in the memory of the participants, this was deemed the most appropriate means whereby to collect the data.

To code the data, preexisting codes drawn from Facione's (1990) conception of critical thinking were used. A preexisting coding scheme was selected because, as was noted above, CT is a difficult concept to define. Due to this difficulty, it was anticipated that a wide array of responses would be used by participants concerning how they understand $\mathrm{CT}$ and their difficulties with understanding and applying CT. In addition, lacking technical vocabulary about CT, it was hypothesized that participants would frame CT via colloquial expressions, such as "challenging opinions". Since these expressions were anticipated to be diverse, open coding could lead to an overabundance of codes and could make it difficult to identify patterns.

Nevertheless, while using a prefigured coding scheme, additional codes emerged via open coding. Creswell (2013) emphasizes adopting this method since a prefigured coding scheme might not account for all the relevant data. Thus, the approach of this study drew upon both coding strategies. In addition, when new codes emerged from that data that were not part of the prefigured coding scheme, these codes were referred to with in-vivo names when possible-i.e., by the names given by the par- ticipants. One exception, however, was if multiple terms were used to refer to a similar phenomenon, in which case only one term was used to serve as the code. A summary of the prefigured and emergent codes are provided in Table 2 below.

\begin{tabular}{|c|c|c|c|}
\hline $\begin{array}{l}\text { Code } \\
\text { Type } \\
\text { Facione } \\
\text { (1990) }\end{array}$ & \begin{tabular}{|l}
\multicolumn{1}{|c}{ Critical } \\
Thinking Skills \\
- Interpretation \\
- Analysis \\
- Evaluation \\
- Inference \\
- Explanation \\
\end{tabular} & \begin{tabular}{|l} 
Critical Thinking \\
Dispositions \\
- Open-Mindedness \\
- Fair-Mindedness
\end{tabular} & Other \\
\hline In-Vivo & $\begin{array}{r}\text { - Thinking } \\
\text { deeply }\end{array}$ & $\begin{array}{l}\text { - Challenging } \\
\text { authority } \\
\text { - Thinking } \\
\text { creatively } \\
\text { - Giving your } \\
\text { own opinion }\end{array}$ & $\begin{array}{l}\text { - Background } \\
\text { knowledge } \\
\text { - Educational } \\
\text { background } \\
\text { - Advanced } \\
\text { knowledge }\end{array}$ \\
\hline
\end{tabular}

To analyze the data, the project used thematic analysis, which focuses on the content of what the participants say (Reissman, 2005). The thematic analysis approach to narrative inquiry was selected because it allowed for an exploration of common understandings and struggles that students have had with CT. As Reismann (2005) notes "the thematic approach is useful for theorizing across a number of cases-finding common thematic elements across research participants and the events they report" (p2-3).

\section{FINDINGS}

Table 3 provides an overview of the findings and shows which participants made references to the identified themes ( $X$ indicates something related to the theme was mentioned at least once and $X X$ indicates aspects related to the theme were emphasized or were reoccurring in the interview). This section will first focus on participant understandings of CT and will then turn to the struggles and challenges that the participants had with CT.

\begin{tabular}{|l|c|c|c|c|}
\hline \multirow{2}{*}{ Table 3. Participant Understandings and Struggles with Critical Thinking } \\
\hline \multirow{2}{*}{ Definitions } & $\mathrm{5}$ & $\mathbf{2}$ & $\mathbf{3}$ & $\mathbf{4}$ \\
\cline { 2 - 5 } & $\mathrm{X}$ & $\mathrm{XX}$ & $\mathrm{X}$ & $\mathrm{X}$ \\
\hline I. Innovative thinking & $\mathrm{X}$ & $\mathrm{XX}$ & $\mathrm{X}$ & $\mathrm{X}$ \\
\hline 2. Independent thinking & $\mathrm{X}$ & $\mathrm{X}$ & $\mathrm{X}$ & $\mathrm{XX}$ \\
\hline 3. Questioning & $\mathrm{X}$ & $\mathrm{X}$ & $\mathrm{XX}$ & $\mathrm{XX}$ \\
\hline Difficulties & $\mathrm{XX}$ & $\mathrm{X}$ & \\
\hline I. Educational differences & $\mathrm{X}$ & $\mathrm{X}$ \\
\hline 2. Background knowledge & $\mathrm{X}$ &
\end{tabular}

\section{Understandings of Critical Thinking}

Student understandings of critical thinking were varied; however, three predominant themes emerged: CT was connected to innovative thinking, independent thinking, and a questioning attitude. These themes were interesting in that CT was more strongly associated with dispositions than skills and abilities. While certain abilities such as analysis and evaluation were mentioned in the course of the interviews, these took on a relatively minor role compared to the dispositions when the participants defined CT and related stories about what CT entailed. These themes are examined more closely below. 


\section{Critical Thinking as Innovative Thinking}

All four participants connected CT with innovative activities, although in nuanced ways. Sometimes CT was related to taking different viewpoints. In this respect, CT was viewed as being a new way of thinking about some idea or problem. This is related to Ennis' (1998) notion that CT involves the disposition to seek alternatives and be open to them. The latter part of the disposition (i.e., be open to them) seems especially important, for the participants not only mentioned acknowledging different positions and ways of thinking but actually thinking about the subject matter in that way. For example, in describing teacher expectations of CT in the U.S., participant two stated that "maybe our teacher will encourage us to think differently using critical thinking."

That said, CT was also connected to innovative thinking in another way: CT was associated with the generation of new ideas. Three participants, for example, connected CT with the advancement of knowledge and discussions in their field. This aspect of innovative thinking is not emphasized in the models of Ennis (1998), Paul \& Elder (2002), and Facione (1990), although it was documented by Moore (20I3) as a definitional strand of $\mathrm{CT}$ as defined by experts in the field (Moore used the term simple originality). Participant 3 , for example, in describing the importance of CT for academic studies, stated that "I think we're entering the conversation in the academic world, and we have to make our own contribution". This same participant would shortly thereafter reiterate this point, saying, "And I wish to do thatto contribute something new." What is perhaps most noteworthy about this aspect of innovative thinking is that it contrasts with the view above (that the thinking process is different in that one thinks about something from an alternative point of view) in that generating a new idea shows a greater concern with the product of thinking (that one produces something different). For example, participant 2 shared a story about a project that came to mind when I asked about experiences with CT.The end of the story (below) shows the importance placed on the generation of new ideas:

For example, I carried out my final year project in Denmark. I inherited some ideas from the papers of scholars in previous years. We carried out the dynamic ratings-they carried out the same ratings for all the power systems, and I combined dynamic ratings and integrated dynamic ratings into the power system, so I get a different idea, quite [unclear] from theirs, quite differently from theirs.

\section{Critical Thinking as Independent Thinking}

Another major theme brought up by all the participants was that $\mathrm{CT}$ was connected to having one's own voice and position on a topic, issue, or problem. This can be contrasted with thinking that is solely based upon what others have to say. Paul and Elder (2002) noted a similar distinction in CT dispositions by contrasting intellectual autonomy with intellectual conformity: autonomy involves thinking for one's self and not simply accepting what others have to say. Participant 4, for example, used the phrase of "establishing one's own ground." Other participants, when talking about this aspect of CT, used language such as "thinking independently" and "giving one's own opinion". For example, Participant I stressed that part of the importance of CT was that it would help graduate students "learn more independently", and participant 2 stated that his/her teacher would encourage students to "raise your own opinions instead of just copying others". Finally, participant 3 connected the lack of CT promotion in the Chinese educational system with the lack of developing independent thinking. It is also interesting to note that, in a certain respect, independent thinking is connected with innovative thinking, for creating a new idea seems to involve giving one's own opinion and establishing one's own ground. While the participants did not explicitly draw this connection, it seems to be present in their work given that all of them emphasized both elements as parts of $\mathrm{CT}$.

\section{Critical Thinking as Questioning}

A final theme that ran across all four participants' conceptions of CT was that CT involved a questioning attitudinal disposition. For some participants, this involved questioning authority figures and received knowledge. For instance, in defining CT, participant 3 noted "When you read something, you do not only accept something as knowledge or fact, but you try to analyze it actively and engage in it and evaluate what is right about it...". This relates to what Moore (2013) called skepticism or a provisional view of knowledge, that is, the disposition to not blindly accept what others have to say but to be careful and critical of the judgement of others. Similar dispositions were noted by Facione (1990) and Ennis (1998), although these authors tended to emphasize more fine-grained distinctions. For instance, Ennis (1998) notes that one disposition of a critical thinker is to seek reasons. This questioning disposition also contrasts with rote memorization, which was noted by participant 3 when stating she/he thought CT skills were not used in her/his undergraduate courses because she/ he would only memorize knowledge but not question it. This experience was echoed by participant 4 , who, in the quotation below explains why she/he believe CT was not part of her/his undergraduate curriculum:

I guess, first of all, critical thinking - the term-has never been explicitly mentioned in any curriculum, and, basically, in our approach to our textbooks and any instruction and so-called knowledge that teachers are imparting, we are expected to be very receptive of whatever the textbook tell us to do and whatever teachers tell us to do without making any questions.

Related to CT as questioning received knowledge, some participants connected CT with challenging the teacher. This seems to be approximately the same attitudinal disposition, except rather than directing a skeptical attitude towards the judgements of the textbook, it is directed at the teacher's judgements. For instance, participant 2 stated that CT involved giving an opinion that contradicts the teacher's. In addition, participant I stated that her/his American counterparts would ask a different type of question than she/he. The participant would go onto state that sometimes this would involve challenging the authority of the professor. As a final note, this disposition seems connected to independent thinking, for in questioning received knowledge, one must have intellectual autonomy and not intellectual conformity (Paul \& Elder, 2002). Thus, it appears that all three dispositions share important relations to one another.

\section{Struggles with Critical Thinking}

The specific struggles that students faced with critical thinking were even more varied than their understandings of CT. In a 
certain respect, this is not surprising, as it is to be expected that individuals will face differing challenges with a set of skills and dispositions as broad as CT. For example, Facione (1990) notes over 10 general dispositions of a critical thinker along with 6 core skills, and Ennis (1998) makes note of I5 abilities associated with CT. Nevertheless, the difficulties noted by the participants were often not explicitly related to CT skills. This may have been because the participants were unaware of the specific labels of the skills, although it may also have been because these aspects of CT were of lesser significance. At any rate, two difficulties stood out in the interviews: Differences with educational expectations and experiences in the U.S. and China as well as the role of background knowledge.

\section{Educational Differences in China and the U.S.}

One perceived challenge with CT was connected to different educational practices between the U.S. and China.All the participants noted differences between the educational systems; however, participants 3 and 4 offered more elaborated responses regarding how they felt their previous experiences did not prepare them to think critically. For example, when I asked participant 4 whether she/he believed that she/he used CT while a high school or undergraduate student in China, the participant responded,"I would say that's a resounding no." Also, excerpt 2 above shows that this participant did not feel CT was a part of the curriculum. Overall, this difference seemed to center on the emphasis placed on the memorization of materials as well as showing deference to the judgements made by authority figures. For example, when I asked participant 3 whether she/he used CT in her/his undergraduate studies, the participant said that students were expected to memorize materials, but they did not have to critically analyze or evaluate. The quotation below is a description of the participant's perception of what a test would look like:

For the literature class, we had the test. The teacher would ask you to define a certain movement in the literature, like history, and to summarize a certain book-or something like that-and to evaluate. In that sense [of] evaluation, we just memorized answers. So yeah, we just write down-it's the way we learn in high school too, like history class, politics class-we memorize how the textbook evaluates the events and movements, and that's how we answer the test. So, yeah, most of the time without your own thinking."

This passage shows that certain CT skills and dispositions were absent from their educational background. For example, the disposition towards independent thinking was not present, nor were skills such as evaluation. This finding matches Tian \& Low (20II) and Paton's (2005) emphasis on the importance of the learning context in explaining the supposition that international (and especially Asian) students struggle with CT.

\section{Lack of Background Knowledge}

Another theme that emerged in student struggles was that $\mathrm{CT}$ is challenging when they have inadequate background knowledge about the topic under discussion. While this was only mentioned by 2 of the participants, it was a reoccurring theme in both interviews, and it was viewed as being a crucial obstacle. Overall, it seems that background knowledge was viewed as a necessary condition for CT; in other words, one cannot critically think without first being informed about the subject matter under dis- cussion. As noted by participant 3 "if I don't really have specific experience, then it's really hard to apply critical thinking." It also seems that the use of certain CT skills and the manifestations of certain CT dispositions may depend more on background knowledge than others. For example, for participant 3, background knowledge was essential for being able to evaluate ideas. On the other hand, for participant I, background knowledge was essential for questioning received knowledge as well as innovative thinking, as is shown below:

I think the most challenging thing would be lack of knowledge [about] what l've learned because I think if I have read more articles or some passages maybe I will have more knowledge about it, so I will raise more questions, but if I just learned something I don't know before, maybe I will just accept this concept. So maybe critical thinking is more reading and more knowledge about it so that you can think from different aspect or you can only learn it from only one way.

This theme is echoed by Weissberg (20I3) and Willingham (2008), both of whom argue for an essential connection between $\mathrm{CT}$ and background knowledge.

\section{DISCUSSION}

Several interesting insights have emerged from this study that contribute to our understanding of why international students struggle with critical thinking. First, in regards to the participants' understandings of $\mathrm{CT}$, the findings show conflicting implications: On one hand, the participants understand CT in ways that is consistent with how it is conceived and theorized in the literature. For instance, the shared conceptions of the participants that CT involves questioning and independent dispositions is widely discussed and has been posited as essential parts of CT models (e.g., Facione, 1990; Paul \& Elder, 2002; Ennis, 1998). This suggests that understanding CT is not at issue, which is consistent with other findings in the literature, such as Lloyd and Bahr (2010). On the other hand, the CT models posited by Facione (1990) and Ennis (1998) also strongly emphasized CT skills and abilities, such as analyzing arguments, evaluating arguments, and forming judgements (e.g., inductions and deductions). This aspect of CT was not widely discussed by the participants (participants I and 2 did not mention analysis or evaluation at all in the interview). The lack of association between CT and these core CT skills might point to part of the difficulty with $\mathrm{CT}$, for this absence might imply a lack of understanding. Nonetheless, other explanations are possible. It may be the case that the participants did not see such skills as being a central component of CT, or, perhaps, the participants lacked the technical vocabulary used to talk about these skills. In either of these cases, the lack of acknowledgement need not imply a lack of understanding.

Another point of interest in the participant's definitions of CT was the wide array of conceptions: Each participant defined CT in nuanced ways. This is related to a problem noted in the literature that there is no definitional consensus. For instance, Phillips and Bond (2004) noted four conceptions in the literature, which included CT as a generic skill, an embedded skill, a component of an autonomous learner, and a critical being. In addition, as already noted, Moore (20l3) categorized seven definitional strands when interviewing professionals who teach CT elements in their classrooms. Finally, Nicholas and Raider-Roth (2016) found that faculty tended to approach teaching CT in different 
ways depending on their discipline. When experts cannot agree on what, exactly, CT is, how can one expect students to be good critical thinkers? In one class, an instructor's conception of CT may not match what another is looking for. Thus, the diversity of definitions might help to explain struggles with $\mathrm{CT}$.

It is important to note, however, that the above considerations do not imply that $\mathrm{CT}$ is defined in contradictory ways nor that there is no common core to $\mathrm{CT}$ running across different definitions, for one explanation of this problem is that CT is a complex concept, that is, CT involves numerous skills and dispositions. Thus, what is perhaps at issue is that only certain parts of CT are latched onto and taught in classroom contexts while other elements are downplayed or neglected. This may lead both instructors and learners to form conceptions of CT that include only a subset of what is espoused in the theoretical literature. Furthermore, with the proliferation of definitions and nuances in theoretical constructs of CT, we may miss the forest for trees, for as Davidson (1998) argues most definitions focus on "rational judgment".

Considering the specific struggles of the participants with $\mathrm{CT}$, the results of this study support literature that has found differences in education to be one of the main obstacle.Tian and Low (20I I), for instance, found that different teaching methodologies and assessment practices in Chinese and American educational systems may account for some struggles Chinese students have faced with CT. In addition, in light of recent research into the role that mood plays in CT (e.g., Lewine, Sommers, Waford, \& Robertson, 20I5) it is interesting to consider whether educational differences could impact student mood (thereby indirectly affecting CT).Another point of interest is that none of the participants mentioned that critically thinking in an L2 was part of the challenge. This has been a growing area of emphasis, and research has found that CT tests show lower results for students when tested in their L2s in comparison to their LIs (Luk \& Lin, 20I5; Floyd, 20 I I). This is not to suggest, however, that this study lends contradictory evidence to those findings, for perhaps the English proficiency of graduate students is high enough that this factor is not important. In addition, the interview did not explicitly ask participants as to whether this was an issue.

A final point worth considering is the importance of background knowledge for CT. The findings of this study support Weissberg (2013) and Willingham (2008) concern that background knowledge is a necessary condition for CT. Thus, this may imply that student struggles with CT are not due to understanding and applying CT, but due to a lack of knowledge about the topics under discussion. In other words, if someone is asked to think critically about some topic on which they know very little, we would expect that they would struggle with this task. Nevertheless, a few caveats are in order: First, if this is the cause of student struggles, then whether a student is international or domestic should make little difference. Second, the role that background knowledge and content plays in CT is an ongoing issue, as was documented by Phillips and Bond's (2004) literature review that included conceptions of $C T$ as a generic skill and as an embedded skill (i.e., one that occurs within specific content).

Finally, additional issues may be at play here. For example, it could be that the issue of having adequate background knowledge is related to identity concerns and classroom power dynamics. Paton (2005), for example, wonders whether the Chinese educational system, in which the teacher has more authority than in
Western contexts, has left Chinese students more reluctant to speak out. Thus, it could be the case that the emphasis placed on background knowledge by the participants is related to power dynamics in the classroom, especially in light of the fact that dispositions such as questioning authority and received knowledge was one of the themes noted above: that is, the participants may not feel comfortable questioning received knowledge because of how they identify themselves in the classroom.

\section{CONCLUSION}

The results of this study add to the scholarship on teaching and learning by addressing the ongoing issue of why international students struggle with critical thinking. Notably, this research corroborates other findings in the literature, such as the importance of background knowledge, definitional disputes, as well as educational differences. All things considered, two findings are worth reemphasizing: First, differences in educational background was an important factor noted by the participants. This could suggest that the participants simply lacked experience and training with CT skills, such as analysis and evaluation. On the other hand, this also could also imply an acculturation issue, for as Tian and Low (20II) note, learning environments create 'small cultures'. Second, participants tended to emphasize dispositional traits in their conceptions of CT to a greater extent than skills and abilities, suggesting that perhaps this aspect of CT is in need of more explicit instruction.

Future research should continue to explore this issue by expanding upon the present study and including more participants in order to obtain a larger sample. In addition, research should examine the experiences of graduate students from countries other than China, especially in light of the finding that educational differences posed a challenge for CT. Finally, research should consider targeting students in particular academic disciplines, for different disciplines may emphasize different CT skills and dispositions, leading to challenges that are discipline specific. This research could also provide information that could help instructors to prepare students for the CT demands encountered in specific disciplines, building on research that has already been conducted on this issue (e.g., Nicholas \& Raider-Roth, 2016). I would end by pointing out that the wide array of individual differences in both how CT was conceived and the struggles that the participants faced indicates that we researchers should be careful not to neglect individual differences, that is, we should also bear in mind that individuals will face unique challenges, which this research has documented.

\section{REFERENCES}

Atkinson, D. (1997). A critical approach to critical thinking in TESOL. TESOL Quarterly, 3 I (I), 7I-94.

Benesch, S. (1993). Critical thinking: A learning process for democracy. TESOL Quarterly, 27(3), 545-548.

Chan, H. M., \& Yan, H. K. (2007). Is There a Geography of Thought for East-West Differences? Why or why not?. Educational Philosophy and Theory, 39(4), 383-403.

Chaplin, S. (2007). A model of student success: Coaching students to develop critical thinking skills in introductory biology courses. International Journal for the Scholarship of Teaching and Learning, I(2), Article 10.

Connelly, F. M., \& Clandinin, D.J. (1990). Stories of experience and 
narrative inquiry. Educational Researcher, 19(5), 2-14.

Creswell, J.W. (20I3). Qualitative inquiry and research design: Choosing among five approaches. $3^{\text {rd }}$ ed. Sage publications.

Davidson, B. W. (1998). Comments on Dwight Atkinson's "A Critical Approach to Critical Thinking in TESOL”:A case for critical thinking in the English language classroom. TESOL Quarterly, 32(I), II9-123.

Davidson, B. W., \& Dunham, R. L. (1997). Assessing EFL student progress in critical thinking with the Ennis-weir Critical Thinking Essay Test. JALT Journal, 19(1), 43-57.

Ennis, R. (1998). Is critical thinking culturally biased? Teaching Philosophy, 2 I (I), I5-33.

Facione, P. (1990). Critical thinking: A statement of expert consensus for purposes of educational assessment and instruction (The Delphi report). American Philosophical Association.

Floyd, C. B. (20I I). Critical thinking in a second language. Higher Education Research and Development, 30, 289-302.

Holmes, N. G.,Wieman, C. E., \& Bonn, D.A. (20I5). Teaching critical thinking. Proceedings of the National Academy of Sciences, I|2(36), I | |99-I | 204.

Kaddoura, M. A. (20I I). Critical Thinking Skills of Nursing Students in Lecture-Based Teaching and Case-Based Learning. International Journal for the Scholarship of Teaching and Learning, 5(2), Article 20.

Lewine, R., Sommers, A., Waford, R., \& Robertson, C. (20I5). Setting the Mood for Critical Thinking in the Classroom. International Journal for the Scholarship of Teaching and Learning, 9(2), Article 5.

Lloyd, M. \& Bahr, N. (20I0). Thinking critically about critical thinking in higher education. International Journal for the Scholarship of Teaching and Learning, 4(2), Article 9.

Luk, J., \& Lin, A. (20I5). Voices without words: Doing critical literate talk in English as a second language. TESOL Quarterly, 49(1), 67-91.

Moore, T. (20I3). Critical thinking: Seven definitions in search of a concept. Studies in Higher Education, 38(4), 506-522.

Murphy, T. G. (20I5). Does Critical Thinking Vary According to Culture? Teaching Philosophy, 38(4), 399-426.

Nicholas, M. C. (20I I). Faculty Conceptualizations and Approaches to Assessing Critical Thinking in the Humanities and Natural Sciences-A Grounded Theory Study. University of Cincinnati.
Nicholas, M. C., \& Raider-Roth, M. (2016). A Hopeful Pedagogy to Critical Thinking. International Journal for the Scholarship of Teaching and Learning, I0(2), Article 3.

Nisbett, R. E., Peng, K., Choi, I., \& Norenzayan, A. (200I). Culture and systems of thought: holistic versus analytic cognition. Psychological Review, 108(2), 291.

Paton, M. (2005). Is critical analysis foreign to Chinese students? In E. Manalo \& G.Wong-Toi (Eds.), Communication skills in university education:The international dimension (Pp. I-I I). Pearson Education.

Paul, R., \& Elder, L. (200I). The miniature guide to critical thinking: Concepts \& tools. Foundation Critical Thinking.

Phillips, V., \& Bond, C. (2004). Undergraduates' experience of critical thinking. Higher Education Research \& Development, 23(3), 277-294.

Rabionet, S. E. (20II). How I learned to design and conduct semi-structured interviews: An ongoing and continuous journey. The Qualitative Report, I6(2), 563-566.

Riessman, C. K. (2005). Narrative analysis. In: Narrative, memory \& everyday life (pp I-7). University of Huddersfield.

Ryan, J., \& Louie, K. (2007). False dichotomy?'Western'and 'Confucian'concepts of scholarship and learning. Educational Philosophy and Theory, 39(4), 404-4I7.

Sobkowiak, P. (2016). Critical thinking in the intercultural context: Investigating EFL textbooks. SSLLT, 6(4), 697-7I6.

Stroupe, R. R. (2006). Integrating critical thinking throughout ESL curricula. TESL Reporter, 39(2), 42-60.

Thompson, C. (2002). Teaching critical thinking in EAP courses in Australia. TESOL Journal, I I (4), I5-20.

Tian, J., \& Low, G. D. (20I I). Critical thinking and Chinese university students:A review of the evidence. Language, Culture and Curriculum, 24(I), 61-76.

Vandermensbrugghe, J. (2004). The unbearable vagueness of critical thinking in the context of the Anglo-Saxonisation of education. International Education Journal, 5(3), 4I7-422.

Weissberg, R. (2013). Critically thinking about critical thinking. Academic Questions, 26(3), 317-328.

Willingham, D. T. (2008). Critical thinking: Why is it so hard to teach?. Arts Education Policy Review, I09(4), 2 I-32. 